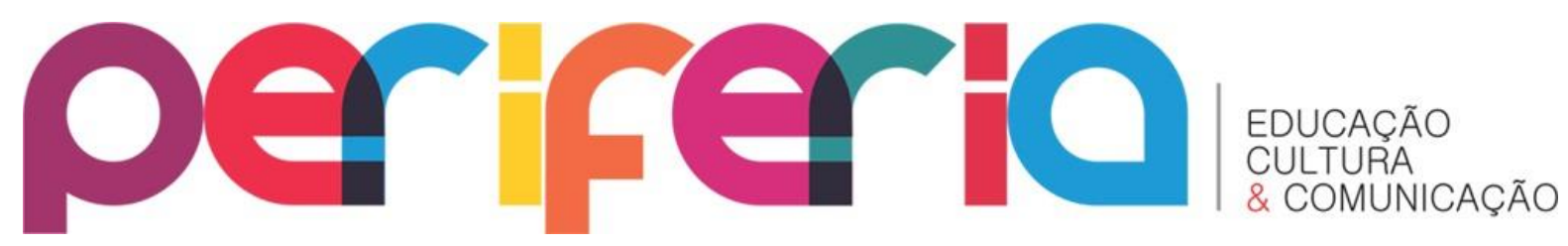

\title{
PRÁtICAS ESCOLARES E POLÍTICAS DE CURRÍCULO: ENTRE O ESTABELECIDO E 0 INTERPRETADO
}

\author{
Suzan Christina Ribeiro ${ }^{1}$ \\ SESI-RJ
}

\section{RESUMO}

O presente texto é parte da pesquisa de dissertação de mestrado que discutiu política(s) de currículo na perspectiva de entendê-las como parte integrante dos espaços escolares. Esta reflexão se deu a partir dos olhares diante da produção curricular no âmbito da rede municipal de Educação do Rio de Janeiro, apontando para o estreitamento e/ou o espaçamento entre os processos singulares da diferença, produzidos na escola e os desdobramentos que esses movimentos podem provocar nas políticas de currículo, que circunscrevem os seus múltiplos contextos.

Palavras-chave: políticas de currículo, diferença cultural, relações socioculturais, práticas escolares.

\section{PRACTICES OF SCHOOL AND POLITICS CURRICULUM: ESTABLISHED BETWEEN AND CONSTRUED}

\section{ABSTRACT}

This text is part of a masters dissertation research that discussed curriculum politics in the perspective to understand them as an integral part of school spaces. This reflection was given from the looks on the curriculum production within the municipal Education of Rio de Janeiro, pointing to the narrowing and / or the spacing between the singular processes of difference, produced in school and the unfoldings that these movements can cause in curriculum politics, which circumscribe its multiple contexts.

Keywords: curriculum politics, cultural differences, socio-cultural relations, school practices.

\footnotetext{
${ }^{1}$ Suzan Christina Ribeiro, pedagoga, professora, mestre em educação pela Faculdade de Educação da Universidade do Estado do Rio de Janeiro, coordenadora de projetos educacionais do SESI-RJ. E-mail: suzanribeiro@oi.com.br
} 


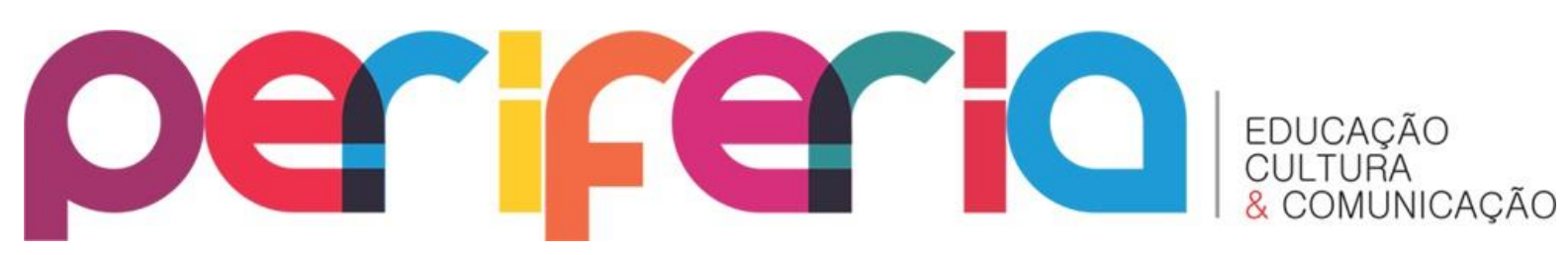

\section{PENSANDO O CURRÍCULO E SUAS ARTICULAÇÕES CULTURAIS:}

É certo dizer que o currículo, como um artefato cultural e social, apresentou-se ao longo da história como uma determinação no âmbito social, fato que implica diretamente nas relações de poder, em visões de sociedade e, consequentemente, na produção de identidades. Portanto, o currículo não é um elemento neutro, de transmissão desinteressada, é ato político que se dá no espaço da escola e nos cruzamentos que se dão, tendo em vista que esse espaço pode ser dinâmico e ativo, o que permite colocar sob suspeita o binômio política-prática curricular.

Para refletir sobre tais questões tomo como base os trabalhos de Stephen Ball e colaboradores (Bowe; Ball; Gold, 1992; Ball 1994a, apud. MAINARDES, 2006, p. 48), na perspectiva de análise do ciclo de políticas, cujo foco pauta-se na articulação entre os processos macro e micro das políticas educacionais. Tais perspectivas posicionam o campo do currículo em diferentes arenas: da política, de contexto e a da prática, onde ocorrem as disputas.

A primeira questão a destacar é a de que, para Ball, (apud. MAINARDES, 2009, p. 304-305), o ciclo de políticas é um método e, assim, não diz respeito à explicação das políticas. Trata-se de pensar em torno das políticas de forma teórica, não descritiva, pensando basicamente na forma como elas são elaboradas. A discussão central desse autor são as políticas educacionais, considerando como são formadas e experimentadas a partir da perspectiva de equidade e da diferença.

Tais perspectivas dão suporte para pensar as problematizações em torno das abordagens do autor e o aporte analítico de que Ball lança mão, a fim de analisar as políticas educacionais, em uma perspectiva crítica para entender como o poder funciona, seus efeitos e suas inadequações.

Uma segunda questão é o fato de que este autor rejeita qualquer possibilidade de que as políticas sejam implantadas, porque há necessidade de traduzi-las em prática e isso se constitui um processo complexo a partir do movimento dinâmico da atuação dos sujeitos que lidam diretamente com tais políticas. Ou seja, estes sujeitos da atuação têm 


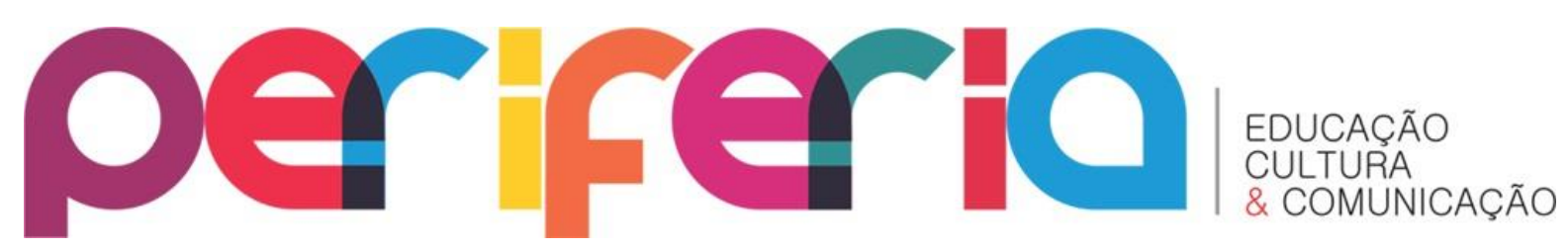

valores pessoais, experiências, fatores que estão dentro de um movimento dinâmico, no qual as políticas precisam ser representadas.

Os estudos de Ball (apud. MAINARDES, 2006, p. 50) abordam o ciclo de políticas a partir de diferentes arenas de produção: o contexto de Influência - relacionado com interesses mais estreitos e ideologias dogmáticas -, o contexto de Produção de Texto representado pelos textos políticos, resultado de políticas e acordos - e o contexto da Prática - onde a política é sujeita à interpretação.

Essa abordagem não constitui etapas lineares, elas se interrelacionam e representam arenas, grupos de interesse, envolvendo disputas e embates (BOWE, et. al., apud. MAINARDES, 2006, p. 96).

A interface entre esses contextos localiza as arenas pelas quais os processos políticos e práticos circulam e se entrecruzam, criando as possibilidades de interpretação desses textos e a sua relação entre teoria e prática.

É importante destacar nesse ponto que, sem estabelecer hierarquias, a abordagem do ciclo de políticas, a partir dos contextos, pode criar possibilidades para uma pesquisa analítica, refletindo, com isso, sobre a totalidade da política tanto nas esferas macropolíticas (contexto de produção de texto) quanto nas esferas micropolíticas (contexto da prática).

Em sua proposição, Ball (2001), explica que é no contexto de influência que os grupos de interesse disputam a definição sobre as finalidades sociais da educação, definindo também o que se constitui legitimamente como ser educado. Nesse contexto, os discursos adquirem legitimidade e formam a base para os discursos políticos.

Há uma relação simbiótica entre o contexto de influência e o contexto da produção de texto. Porém, o primeiro relaciona-se com os interesses e com a ideologia e, o segundo, com os textos políticos que podem ser: textos oficiais, comentários formais ou informações sobre os textos oficiais. Esses textos políticos resultam de acordos e disputas. Segundo Ball (2001) é importante destacar a distinção entre "política como texto" e "política como discurso". Os textos das políticas terão sempre uma pluralidade de leituras e sofrem muitas influências, dada à pluralidade de leitores. Assim, os textos políticos tendem a ter algumas 


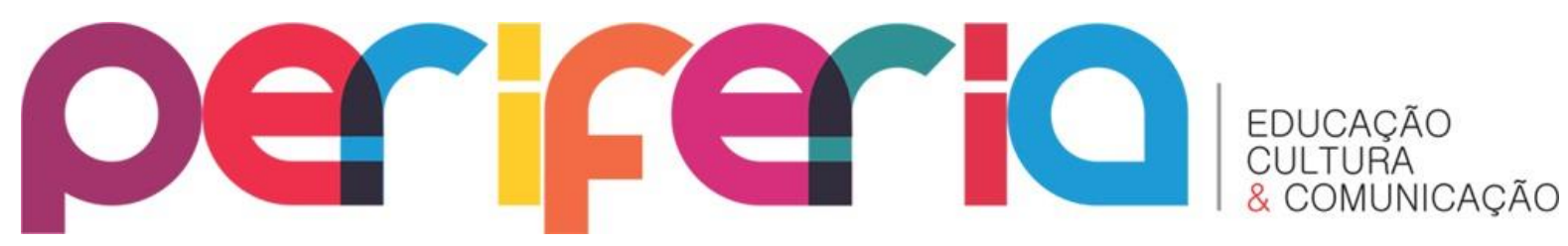

dessas influências reconhecidas como legítimas e outras como não legítimas, porque são o resultado de acordos e agendas políticas.

Segundo Mainardes (2006, p. 97):

Os textos políticos são resultado de disputas e compromissos. A política enquanto discurso enfatiza os limites do próprio discurso. As políticas podem tornar-se "regimes de verdade" (FOUCAULT, não tem data no texto) na qual apenas algumas vozes são consideradas como legítimas. Política como texto e política como discurso são noções complexas porque os textos não são apenas o que eles parecem ser em sua superfície e os discursos, numa concepção foucaultiana, não são independentes de história, poder e interesses (BALL, 1993a).

O contexto da prática aponta as disputas entre os contextos político e o de influência, onde há possibilidade de pensar os processos de diferença cultural na escola, pois, traduz o exercício da política como texto onde pode representar as mudanças de significado dessas arenas.

Para Mainardes (2006, p. 96), com base nos estudos de Ball, os profissionais que lidam com as políticas não estão isentos, eles representam, na prática, as suas interpretações sobre as políticas educacionais e estão implicados nesse processo.

No âmbito desta pesquisa concentrei minhas análises no contexto da prática, sem desconsiderar as relações entre os diferentes contextos, entendendo que tais contextos se interrelacionam e, a partir deles, podem ser produzidos outros elementos que favoreçam a interpretação do contexto da prática. Quero dizer com isso que o contexto da prática pode adotar as percepções dos atores envolvidos, principalmente, porque é na prática que os contornos podem ser elaborados e produzidos, contingencialmente, tendo em vista que não há possibilidade, numa perspectiva crítica, de se conceber fixações absolutas.

\section{NA ESCOLA, LEITURAS E RELEITURAS PRODUZINDO POLÍTICAS CURRICULARES:}

A pesquisa empírica se lançou às reflexões a fim de encontrar no espaço escolar os elementos para se pensar a(s) política(s) de currículo(s), em uma perspectiva subjuntiva, 


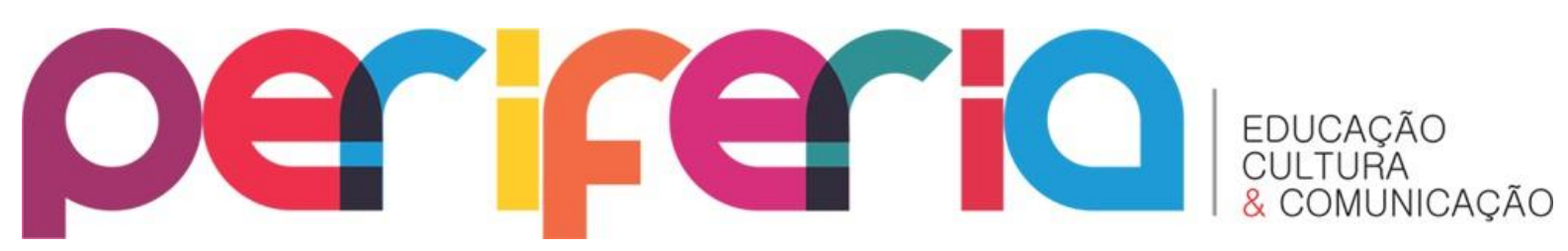

porém, crítica, no sentido de encontrar o local de sua ressignificação, os seus deslocamentos e os seus híbridos.

Com esse propósito, a preocupação central na pesquisa de campo foi em investigar como as políticas de currículo são experimentadas no corpo da escola. E, ainda, como se dá tal movimento investigativo, a partir dos estudos de conceitos centrais, tais como: diferença, cultura, conhecimento, posto que essas questões estejam imbricadas no espaço escolar.

Recorro, então, no desenho dessa pesquisa, a uma perspectiva de inspiração etnográfica orientadora para a pesquisa em uma escola da rede municipal, na 2a Coordenadoria Regional de Educação (CRE), do Rio de Janeiro, empregando como estratégias para a investigação das articulações entre os contextos: a observação do cotidiano, as entrevistas com os gestores, professores/as e alunos/as, com o objetivo de identificar desejos, articulações, ou ainda de novos arranjos que podem se dar a partir das políticas curriculares estabelecidas, além de análise do texto da proposta curricular da rede e das produções da escola, observando como esses diferentes textos se hibridizam.

$\mathrm{Na}$ perspectiva de reinterpretação das políticas, reconhecemos no contexto da prática o espaço em que os novos contornos podem se dar, o que mostra a relevância do recorte da pesquisa e da realização das observações e entrevistas como estratégias para a sua realização. De acordo com Mainardes (2006):

Os autores indicam que o foco da análise de políticas deveria incidir sobre a formação do discurso da política e sobre a formação do discurso da política sobre a interpretação ativa que os profissionais que atuam no contexto da prática fazem para relacionar os textos da política à prática. Isso envolve identificar processos de resistência, acomodações, subterfúgios e conformismo dentro e entre as arenas da prática, e o delineamento de conflitos e disparidades entre os discursos nessas arenas (MAINARDES, 2006, p. 50).

Analiso a forma como os textos políticos dialogam com/na prática, ou seja, discutir uma interpretação legítima dos profissionais em relação a tais textos, tendo em vista a complexidade desse processo. A seguir parto para uma análise da forma como os discursos e as práticas podem traduzir-se em movimentos de hibridação, dado todos os 


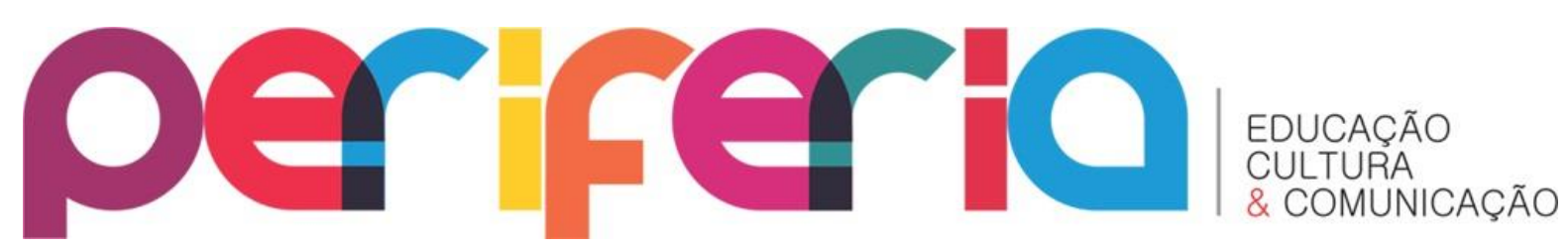

fatores que influenciam a "arena teatral" (BALL, apud MAINARDES e MARCONDES, 2009, p. 305), meio em que pode se traduzir o espaço da escola.

A questão da arena teatral, defendida por Ball, refere-se à possibilidade de interpretação que os profissionais encontram diante das políticas de currículo, quando existe um processo social e pessoal desses "atores", interessados em representar tais propostas nos contextos materiais.

A partir do contexto da prática, a busca estava em compreender as articulações entre currículo, cultura e conhecimento, partindo das observações do cotidiano escolar, de uma turma do 4ำ ano de uma escola municipal do Rio de Janeiro, que atende da Educação Infantil ao 9o ano do Ensino Fundamental.

Já para pensar as políticas curriculares, com base nas diferenças culturais, percorri os estudos de Homi Bhabha (1998) e Canclini (2008), partindo do conceito de hibridismo, compreendendo as interpretações que podem ser tecidas no espaço escolar, necessárias para a ressignificação do currículo como processos de hibridação. Nesse diálogo encontro a possibilidade de pensar criticamente uma política curricular articulada ao conhecimento, à cultura e à diferença, uma política que "inaugure" um espaço de educação onde o "estabelecido" deixa de ser verdade e, com isso, tome lugar a contingência.

As questões centrais de problematização da pesquisa foram: 1. Os professores/as dialogam com os documentos oficiais sobre as políticas curriculares? 2. A escola identificase como espaço legítimo de diferença cultural? O que é realizado a partir desse reconhecimento? Como são deflagrados os processos de aprendizagem? 3. Com que concepção de conhecimento a escola opera? Nesse estudo trago um recorte da pesquisa, concentrando-me em como a escola lida com a diferença, observando-a como campo de negociação e produção.

As observações se deram dentro da sala de aula de uma turma do 40 ano do Ensino Fundamental, em 2010, e de uma turma do 3o ano, também do Ensino Fundamental, em 2011. As turmas reúnem grupos de alunos/as de diferentes municípios do Estado do Rio de Janeiro, principalmente da Baixada Fluminense. Em sua maioria são filhos/as de responsáveis que trabalham em casas de família ou no comércio no entorno da escola 


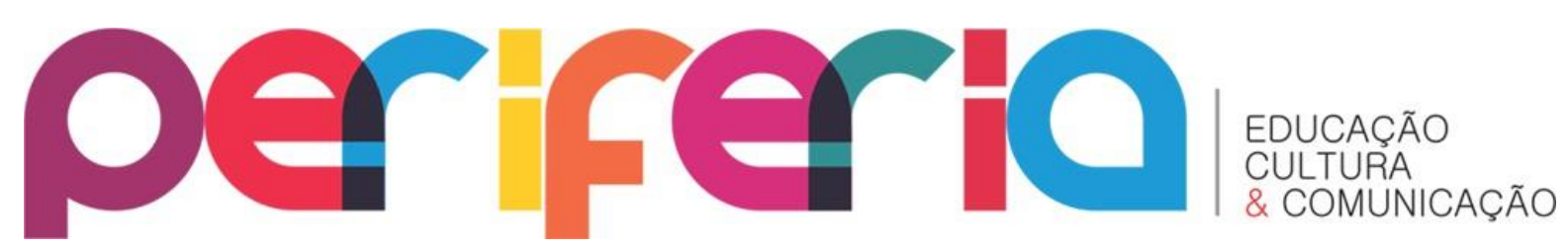

sendo uma parte de alunos/as moradores de uma comunidade pacificada em 2010, próxima à escola.

Essa escola foi fundada há mais ou menos cem anos e o prédio foi doado pela família de um dos ministros da Educação, o que remonta à história da Educação Brasileira. O prédio é tombado pelo Patrimônio Histórico e, portanto, a realização de obras de melhoria se torna um processo mais burocrático. A escola tem uma sala onde funciona a direção da escola e secretaria, outra da coordenadora pedagógica, uma sala de professores, um refeitório e uma cozinha, uma quadra de esportes (não é coberta e não tem a metragem exigida pela legislação), um parque infantil e sete salas de aula.

As análises partem da forma de organização desse espaço e encontro alguns elementos que podem traduzir-se em espaço regulador porque as disciplinas do currículo comum são valorizadas na medida em que se organizam e se estruturam de forma a manter a hegemonia dominante da organização linear do trabalho. E a organização do tempo escolar evidencia uma escola entendida como espaço de ordenação e disciplinamento.

Ao mesmo tempo em que entendo as dificuldades em torno de criar outras possibilidades para pensar os tempos e a forma disciplinar, porque existem determinações da Secretaria Municipal de Educação (SME), esses profissionais são convocados a pensar essa trajetória em busca dos novos contornos e interpretações para o desenvolvimento das políticas locais.

Minha percepção é de que os profissionais não se sentem autorizados/as a produzir o currículo, embora o produzam. Talvez, a manutenção de uma perspectiva de educação tradicional e conteudista, se dê por essa falta de autorização que eles/elas têm em relação a si próprios como profissionais e, com isso, a reprodução do currículo prescritivo enviado pela SME.

Nessas observações tenho me deparado com ambivalências na arena do ciclo de políticas: embora o grupo de profissionais busque novas ressignificações, caem em determinismos impostos pelos processos e orientações vindos da SME. A segunda problemática talvez ocupe o espaço de interlocução e de articulação desse grupo que não 


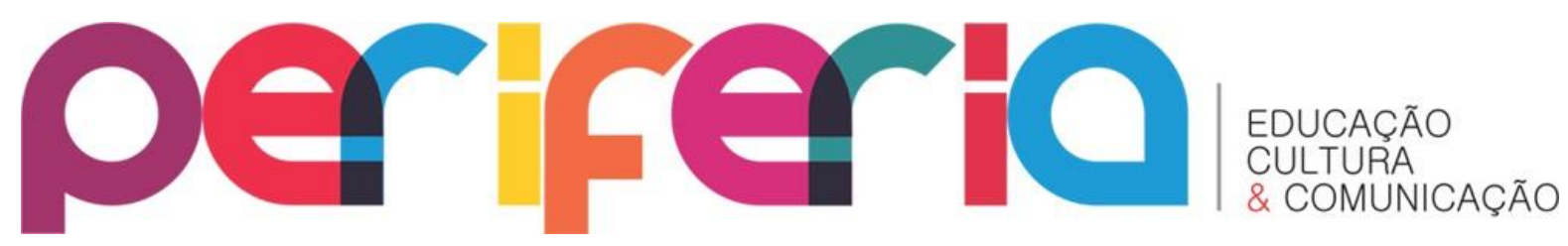

consegue vencer tantos anos sob a égide de um sistema regulador e disciplinar. A última observação ocupa a mão e a contramão desse processo que diz respeito ao grupo de alunos/as em que a diferença cultural ocupa espaço periférico.

Não podem ser desprezadas as tentativas do poder colonial de aniquilação das culturas subalternas, com seus procedimentos para marcar as diferenças, fechando classes de coisas e expelindo os elementos não classificáveis. Uma das principais estratégias discursivas do poder colonial para fixar sentidos e inviabilizar a diferença - o estereótipo - é, no entanto, para o autor, ambivalente. E essa ambivalência nos impõe outra forma de entender o poder e a agência. (Bhabha apud MACEDO, 2006, p. 106):

Talvez o conceito de ambivalência responda teoricamente quanto ao posicionamento frente ao poder cujos discursos/práticas ainda prevaleçam, embora as reinterpretações aconteçam, o conhecimento oficial é predominante.

$\mathrm{Na}$ perspectiva de pensar as negociações e as práticas, apresento algumas observações e análises das propostas de trabalho de sala de aula que trazem elementos para pensar como as políticas curriculares se dão nessa prática, as formas disciplinares e a desarticulação entre as culturas.

Em entrevista realizada em junho de 2011 com a professora Fernanda ${ }^{2}$. Quando pergunto se ela percebe se existem diferentes culturas e saberes na sala de aula e como lida com essas diferenças, ela diz:

O currículo não considera essa questão especificamente, está tudo unificado. $\mathrm{O}$ que eu acho é que lidar com as diferenças, sejam elas culturais, de hábitos, de cor, de religião, de saberes diferentes, toda diferença causa um pouquinho... Inicialmente vai e você tem que trabalhar isso, trabalhando como... Conversando... Você não gosta disso, então vamos respeitar. A criança é muito natural, a criança acha que quer saber aquilo e o amigo tem que querer também e briga por isso. Então a gente tem que lidar com isso, eu não vejo essa diferença de hábitos e de saberes. É o que eu falei agora, de alguns que não tinham dificuldade de trabalhar troco, as crianças da comunidade, porque estavam acostumadas. E, aqui, são poucas as crianças de comunidade, a maioria não é, e tem dificuldade. São saberes

\footnotetext{
${ }^{2}$ Nome fictício. Todas as entrevistas que compõem a pesquisa foram gravadas e transcritas com a autorização das professoras, que também permitiram seu uso, desde que preservando seu nome, tal como consta do termo de declaração livre e consentida (modelo da Comissão de ética e Pesquisa - UERJ), que assinaram.
} 


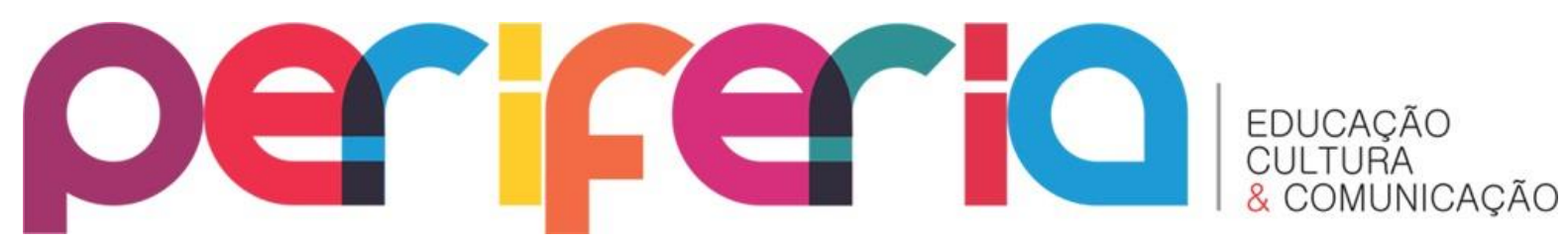

diferentes, como lidar com isso? Vai chegar uma hora em que eu tenho que dar uma aula quase que particular. Como fazer isso sem ajuda dentro da sala de aula? Fica difícil. Esse não aprendeu; assim, eu tenho que fazer diferente com ele, ou esse aluno está muito disperso, é muito complicado. Por isso, eu falo para você, a teoria é a teoria e na prática você precisa fazer uma articulação.

Nos embates conflituosos a respeito das diferenças observa-se que se aspira a um ideal específico de comportamento e de sujeito. Talvez um ideal vazio, pois o que constitui o ser humano é a diferença. Outra observação permite avançar nessa discussão: em 31 de maio de 2011 o grupo de alunos/as trocava adesivos no início da aula. A professora Fernanda explicou que esse grupo tem dificuldades de relacionamento e, a partir das trocas dos adesivos entre eles/elas, a situação vem melhorando. Na observação da professora, as alunas negras se separavam das alunas brancas, os grupos não se misturavam.

Nessa atividade, observei o quanto os alunos/as se envolveram e pude ouvir algumas conversas entre eles e elas sobre onde compram os adesivos, o valor da cartela, a banca de jornal onde está mais barato, a quantidade de adesivos que a vizinha tem etc. As conversas entre o grupo de alunos/as expressava o quão importante estava sendo aquela atividade; havia prazer, e as trocas não obedeceram a regras ou diferenças sociais, étnicas ou qualquer outra era simplesmente o prazer de trocar os adesivos.

Contudo, o que se espera dessa troca? Em entrevista, a professora Fernanda amplia essa questão, que julgo importante para este texto.

Passei a dar um tempo livre para isso (a troca dos adesivos) ser feito. Ficam quinze minutos, dez minutos, uma foi trocando, a outra foi comprando e aquele grupo que estava com relacionamento difícil acabou se aproximando muito. E leitura, eu fiz uma leitura com eles muito legal, os mais amadurecidos perceberam, diante das minhas perguntas depois, não sei se vocês conhecem o texto "A pipa e a flor". [...] A gente tem uma briga com o que a gente passa na escola e com o que é passado na família, que é uma coisa muito forte. [...] Os valores mudam muito, os valores mudam de acordo com a classe social, muda sim, muda porque muda. Eles têm como normal vários procedimentos que para a gente não é considerado adequado, não é dentro do convívio. Eu tenho uma aluna, a Catarina (nome fictício), que é muito masculinizada, no sentido de jogar futebol, falar palavrão, aquele jeito 


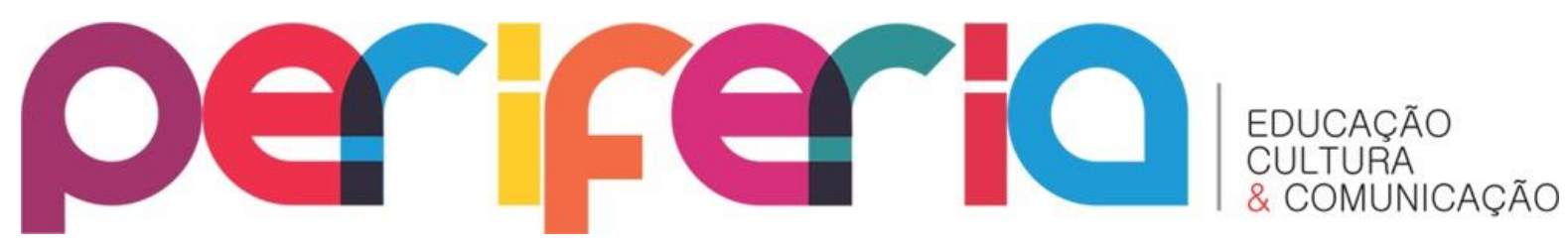

dela. É ela, a Ana e a Carla, elas têm um jeito de falar alto, às vezes estão falando alto com o amigo do seu lado, o que é hábito muito mesmo de comunidade. Todos os alunos, lá onde eu trabalhei antes, falavam alto, é uma coisa deles mesmos, eu não sei por que, mas a gente sente a diferença, e a escola faz o quê? A escola tem que aceitar, sim, a escola não pode chegar para eles e falar assim, 'olha... ' E excluir o aluno. Mas, ali, dentro do refeitório, você está berrando, falando alto com o seu colega da frente, por que você está fazendo isso? Fala baixo, ele está na sua frente, pra que você está falando alto desse jeito? Eu estou dando um exemplo. São os valores em relação a outras coisas também. A facilidade que eles têm de ver muitas coisas na vida daquela comunidade, eles participam. Muitos pais e mães dormem com seus filhos no mesmo local, e os alunos são novinhos e já sabem de várias coisas. Como eu posso chamar isso? É cultural, mas são vários e os pais estão dormindo com os filhos no mesmo local e têm a vida íntima deles (Diário de Campo, 31/05/2011).

São essas negociações que o espaço da escola permite? Pensá-las para além das fixações e reconhecer a inauguração de um novo tempo é sublinhar que a PósModernidade, talvez por efeito dos globalismos, traz encarnada novas formas de pensar as relações e as identidades - diferentes e contingentes - refletidas no espaço da escola.

A atividade de troca dos adesivos foi usada para aproximar o grupo de alunos/as, de acordo com o depoimento da professora. Porém, o que ficou dessa experiência foi um modo de regular o comportamento social, nesse caso, um controle para o exercício de manutenção disciplinar. O fato de trocar os adesivos não produziu no grupo de alunos/as uma forma de pensar as relações e seus efeitos, e sim, uma representação simbólica de mudança de padrão de comportamento.

Com Hall (2006, p. 12), é possível pensar que:

Argumenta-se, entretanto, que são exatamente essas coisas que agora estão "mudando". O sujeito, previamente vivido como tendo uma identidade unificada e estável, está se tornando fragmentado; composto não de uma única, mas de várias identidades, algumas vezes contraditórias ou não resolvidas. Correspondentemente, as identidades, que compunham as paisagens sociais "lá fora" e que asseguravam nossa conformidade subjetiva com as "necessidades" objetivas da cultura, estão entrando em colapso, como resultado de mudanças estruturais e institucionais. O próprio processo de identificação através do qual nos projetamos em nossas identidades culturais tornou-se mais provisório, variável e problemático. 


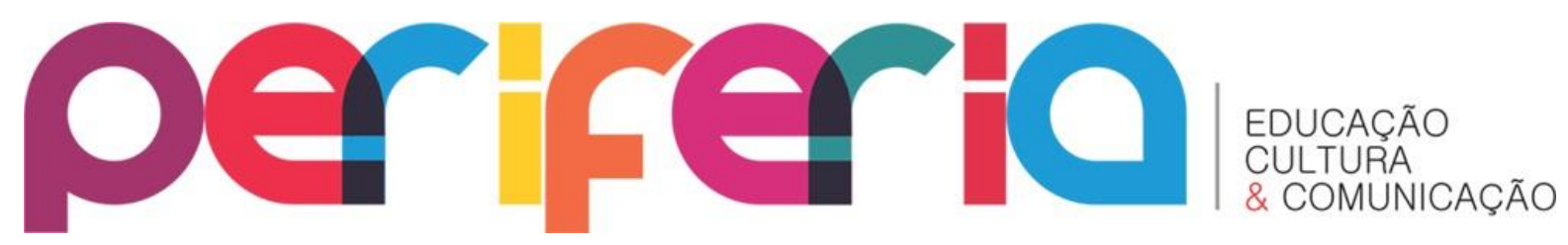

Pensar sobre essas novas identidades é imaginar um sujeito para além de uma identidade única, porque esta se modela continuamente a partir dos diferentes contextos. Não acredito que os discursos sobre os deslocamentos em torno dos processos de identidade e das diferenças culturais sejam uma característica dos subalternos, sob a alegação de que a cultura "deles" cause conflitos na escola. Então quem é esse Outro que a escola não reconhece como sujeito com identidade e cultura legítimas e que a partir disso o rotula, despejando sobre Ele os males sociais refletidos no espaço escolar?

Essa é uma questão importante tendo em vista que o Outro não é aquele que o imaginário social definiu e que os "sociólogos pensaram muitas vezes, unificado e bem delimitado" (HALL, 2006). Talvez a escola precise refletir as novas produções de sentido sobre a cultura, o sujeito e a identidade, pois o mundo está se transformando em uma grande cadeia global onde não cabem determinismos e classificações. As vozes dos subalternos estão mudando o cenário. As ferramentas e as fantasias nostálgicas do passado, portanto, não respondem mais.

É especialmente aqui que as revoluções da cultura a nível global causam impacto sobre os modos de viver, sobre o sentido que as pessoas dão à vida, sobre suas aspirações para o futuro - sobre a "cultura" num sentido mais local (HALL, 1997, p. 2).

Essas mudanças não são uniformes. Elas são complexas e, por isso há os conflitos pelas tentativas homogeneizadoras da cultura, do agir, do pensar, do sujeito e do conhecimento. Importante sinalizar que "a cultura global necessita da 'diferença' para prosperar - mesmo para convertê-la em outro produto cultural para o mercado mundial" (HALL, 1997, p. 3).

Creio que tais mudanças, sobretudo na visão do sujeito frente ao seu processo de aprendizagem, constituam uma forma de reescrita das políticas curriculares, com vistas não somente a pensar seu novo sentido, mas para, ao dar-se conta de que a escola se favorece do "caos globalizante", reinventar outras formas de ensinar. (LOPES, 2008, p. 10). 


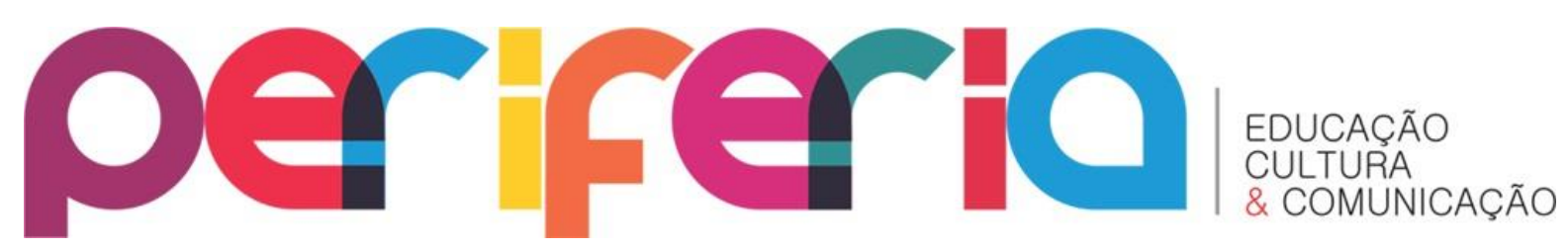

\section{CONCLUSÕES}

Defendo uma perspectiva que reflita sobre uma educação capaz de perceber no "outro" as suas possibilidades, reconhecendo também o que há de saber em cada sujeito, base para articular os conhecimentos e as culturas, promovendo assim, um currículo dinâmico, ativo e real. Defendo o fato de que as tensões sobre a política de currículo possam ater-se ao desafio de pensar os sujeitos com suas diferenças, lembrando que a escola se constitui um espaço de articulação de culturas, de intenções e subjetividade, afastada assim de uma perspectiva de currículo prescritivo e/ou funcional.

A sociedade contemporânea é marcada pelas identidades não fixas e pela necessidade de pensar sobre as categorias de classe ou gênero com vista ao afastamento das suas singularidades. E a escola está inserida nessa perspectiva em que as diferenças constituem sujeitos que ocupam o espaço de fronteira e, a partir de suas articulações, produzem as diferenças culturais. Creio que são sobre essas diferentes formas de pensar as novas subjetividades que a escola está sendo convocada.

É nessa reflexão de grande monta que a escola poderá dar conta das suas aflições, negociar suas possibilidades e as novas estratégias de lidar com a diferença.

Esses "entre-lugares" fornecem o terreno para a elaboração de estratégias de subjetivação - singular ou coletiva - que dão início a novos signos de identidade e postos inovadores de colaboração e contestação, no ato de definir a própria ideia de sociedade. (Bhabha 1998, p. 20)

Creio que é no deslocamento - entre-lugar - que podem negociar os valores culturais da diferença. Embora essa negociação seja complexa e carregada de valores que mistura passado e presente, que muitas vezes são convocados para negar as novas formas de identidade e de classe, é nesse viés que encontramos as articulações sociais. E a escola precisa pensar essas articulações, tomando por base os próprios sujeitos com os quais lida cotidianamente, rompendo com as categorias cristalizadas ou vistas de forma estática. 


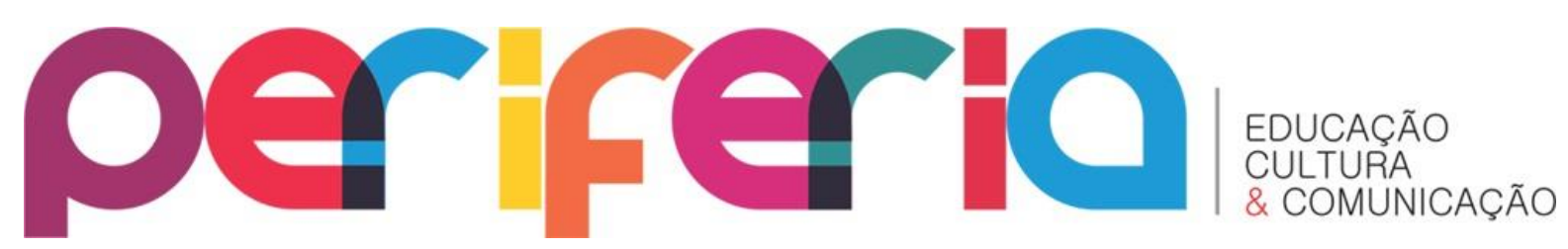

A escola constitui, eminentemente, um espaço de misturas de identidades e classes e é justamente a partir dessas articulações que há produção. De outra forma, é pensá-la estática, a-histórica e apolítica.

Nesta perspectiva gostaria de considerar que as práticas escolares podem traduzirse nas diferentes formas de interpretar a articulação entre cultura e currículo não como seleção de culturas, mas a partir do que há de articulação entre esses elementos, tendo em vista que a escola ao produzir conhecimento, também produz cultura.

\section{REFERÊNCIAS BIBLIOGRÁFICAS}

BALL, Stephen. Diretrizes Políticas Globais e Relações Políticas Locais em Educação. Currículo sem Fronteiras, vol. 1, n2, p. 99-106, jul./dez. 2001. Disponível em: http://www.curriculosemfronteiras.org/vol1iss2articles/ball.htm

BALL, Stephen J., BOWE, Richard (1992). Subjet departments and the "implementation" of National Curriculum policy: an overview of the issues. Journal of Curriculum Studies, v. 24, n. 2, p. 97-115 apud LOPES, Alice Casimiro. Discursos nas políticas de currículo. Currículo sem Fronteiras, Rio de Janeiro, v.6, n.2, pp.33-52, jul/dez. 2006.

BOWER, R.; BALL, S.; GOLD, A. Reforming education apud MAINARDES,Jefferson. Apud MAINARDES, Jefferson; MARCONDES, Maria Inês. Entrevista com Stephen J. Ball: Um diálogo sobre Justiça Social, pesquisa e política educacional. Educação e Sociedade, Campinas, v. 30, n. 106, pp. 303-318, jan./abr. de 2009.

BHABHA, Homi. O local da cultura. Belo Horizonte: Editora da UFMG, 1998. . O local da cultura. Belo Horizonte: Editora da UFMG, 1998.

CANCLINI, Néstor Garcia. Culturas Híbridas. 4 ed. São Paulo: EDUSP, 2008.

HALL, Stuart. A centralidade da cultura: notas sobre as revoluções culturais do nosso tempo. In:THOMPSON, Kenneth (Org.). Media and Cultural Regulation. Inglaterra: Educação \& Realidade, Inglaterra, n p. 23, 1997.

LOPES, A. C. MACEDO, E. O pensamento Curricular no Brasil. In LOPES, A.C.

Currículo: debates contemporâneos. São Paulo: Cortez Editora, p. 13-54, 2002.

. Nota Introdutória - Cultura e Política: implicações para o Currículo. Currículosem Fronteiras, Rio de Janeiro, v. 9, n.2, pp. 5-10, jul/dez de 2009.

MACEDO, Elizabeth. Currículo: política, cultura e poder. Currículo sem Fronteiras, Rio de Janeiro, v. 6, n.2, pp. 98-113, jul./dez. 2006. Disponível em http://www.curriculosemfronteiras.org

MAINARDES, Jefferson. A abordagem do Ciclo de Políticas e suas Contribuições para Análise da trajetória de Políticas Educacionais. IN: Atos de Pesquisa em Educação, PPGE/ME FURB, v.1, maio/agos. 2006

SKLIAR, Carlos. A educação e a pergunta pelos Outros: diferença, alteridade, diversidade e os outros "outros". Ponto de Vista, Florianópolis, n. 05, p. 37- 49, 2003. 